\title{
DESIGN AND IMPLEMENTATION OF AN ADIABATIC CHAMBER TEMPERATURE CONTROL DEVICE FOR CLINICAL USE
}

\section{JUAN GRADOS, WILVER AUCCAHUASI, RICARDO GUTIERREZ, JESSICA MEZA, SANTIAGO RUBIÑOS, JHONNY PERALTA, KEVIN PAUCAR \& JIM PAREDES}

\author{
Research Scholar, Universidad Nacional Del Callao, Lima, Perú
}

\begin{abstract}
The diabetic chamber, is a very important equipment in medical establishments, for the thermal treatment, in this work the purpose is the contribution in the implementation of a solution based on the design and implementation of a device for the control of the temperature in these chambers, for clinical use. In the design of the temperature controller, the elements used for the temperature control system, the system hardware design, as well as the software design is detailed. It also mentions possible system errors. The results present the tests and design results. As a recommendation the selection of the type of control is presented.
\end{abstract}

KEYWORDS: Temperature Controller Design, Hardware and Software, Temperature Control System

Received: Jun 05, 2020; Accepted: Jun 25, 2020; Published: Jul 30, 2020; Paper Id.: IJMPERDJUN2020532

\section{INTRODUCTION}

Engineering contributes to the improvement of people's quality of life because they are always in search of the most efficient way to solve a problem or meet any need that arises. In that sense, the objective of this study is to address the need for a temperature control for an adiabatic chamber for clinical use, for which the electronic design of said device is presented.

Thermodynamics is a branch of Physics that studies the transformations of energy and its transfers, especially the interrelationships between work, heat and temperature. There are two laws that govern it and which help us to understand it and based on it apply it in the design and calculation of machines or thermodynamic processes that are used in the solution of many practical problems, as is the case of the design developed here thesis. These laws are the ones mentioned below.

First Law of Thermodynamics: This first law is a generalization of the principle of conservation of energy and defines that the change in the internal energy of a system is equal to the sum of the energy transferred to the system as heat and labor. Second law of thermodynamics: This law is enunciated as follows by the German physicist-mathematician Rudolf Clausius: "It is impossible that a machine acting by itself and without the help of an outside agent, transport heat from one body to another that has a higher temperature than the first".

Mollier Diagram: It is the most useful diagram and the one that is used most frequently for the calculation of calculations in refrigeration, it is also known as a pressure - enthalpy diagram. It is called that because the pressure and enthalpy properties are shown in the vertical and horizontal axes respectively, but it also shows the saturation lines, the liquid and vapor regions of the refrigerant, constant temperature lines, constant volume, entropy constant. In addition, some diagrams show the quality, that is, the percentage of vapor mass in a mixture of 
liquid and steam.

\section{METHODS AND MATERIALS}

The methods and materials are composed, by the procedures carried out in the development of the investigation, which consists of block diagram, electronic design, the software design and the connection diagram, which are detailed below.

\subsection{Blocks Diagram}

The design of this control system consists of two important parts that together help to achieve the control objective, one of them is the hardware and the other is the software. In figure 1, the block diagram is presented that will allow a better understanding of the design to be developed in the present investigation:

The system has a user interface that will allow you, through the use of a matrix keypad, to enter desired temperature values that are within the operating range of the equipment. In addition, the temperature inside the camera will be displayed with the use of an LED screen.

Figure 1 shows a temperature controller is an instrument used for temperature control. The temperature controller has an input from a temperature sensor and has an output that is connected to a control element such as a heater or fan.

The adiabatic chamber that will be tested is connected to a vapor compression refrigeration module, which allows the temperature of the chamber to be lowered by manually regulating the expansion valve found in the aforementioned educational module.

Figure 2 shows as mentioned earlier, the adiabatic chamber is interconnected to a refrigeration system, which consists of a refrigeration plant of the J. \& E brand. Hall Products charged with R134a refrigerant. This plant is used in the hospital and works independently of the camera.

Figure 3 shows the zero-crossing detector circuit has been included in the design of the main control circuit, which will allow the microcontroller to send a control signal to the resistor power control module. Figure 4 shows the designed circuit:

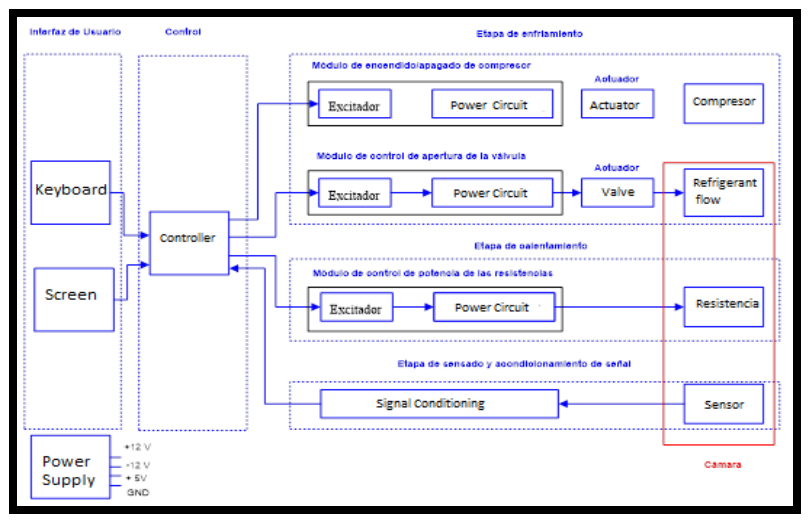

Figure 1: Block Diagram of the Proposal. 


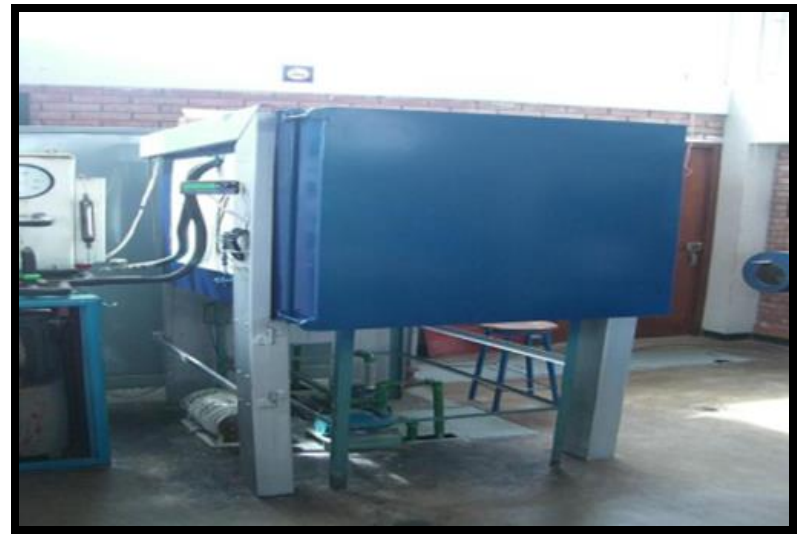

Figure 2: Adiabatic Chamber.

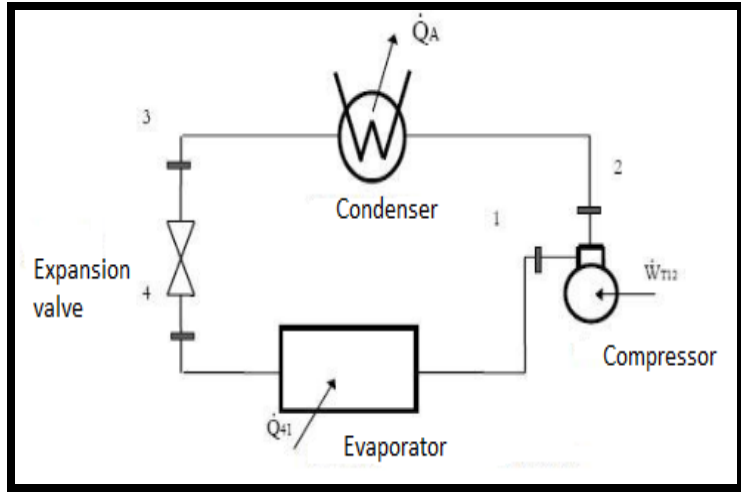

Figure 3: Adiabatic Chamber.

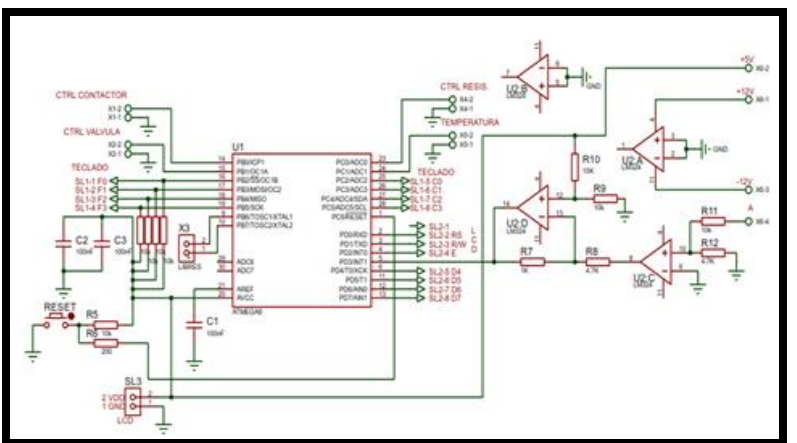

Figure 4: Schematic Diagram of the Main Control Circuit.

\subsection{Electronic Design}

Sensor module design and signal conditioning: In this stage the temperature value inside the chamber is obtained by means of a temperature sensor that delivers a signal that will be conditioned so that it can work properly with the Atmega8 A / D converter.

The signals provided by thermocouples in general are the order of microvolts, so they need to be amplified. The AD595 is a CI designed to amplify the signals of the type $\mathrm{k}$ thermocouples, which is why it will be used in this design. This integrated delivers $10 \mathrm{mV} /{ }^{\circ} \mathrm{C}$ and also has cold junction compensation that eliminates the effect of ambient temperature on the measurement. The schematic diagram of the circuit is presented in Figure 5:

Figure 5 shows Design of the resistor power control module: This module allows you to control the power of the heating resistors and at the same time protect the microcontroller because it allows you to separate the power stage from 
the control stage.

As already mentioned the fundamental components of this circuit are the optocoupler and the triac. Figure 5 shows the design made:

Figure 6 shows Design of the valve opening control module: To control the flow of refrigerant to the chamber and thereby decrease its temperature, the Danfoss AKV10-1 electronic expansion valve will be used, which has a $220 \mathrm{~V}$ AC coil at $60 \mathrm{~Hz}$.

Figure 7 shows While it is true that as in the case of the power control of the electric resistors, a triac was chosen; the chosen model is another (BTA 136) because here it is not necessary for the triac to handle a current of 12 A but a current less than $1 \mathrm{~A}$ since the coil is powered at $220 \mathrm{Vac}$ and is $10 \mathrm{~W}$.

Compressor on and off module design: In order to start the cooling stage, it is necessary to turn the compressor on or off if it is not necessary to cool. The card to be designed here allows you to fulfill that task.

This circuit is identical to that designed for the opening control of the electronic expansion valve, with the difference that it will be used here to energize or not the contactor that will turn on the compressor when it is required to lower the temperature inside the adiabatic chamber. Figure 7 shows the designed circuit:

Figure 8 shows Power circuit design: An essential part for the operation of the designed circuits is that they have a power supply; the design of this circuit is done after having defined the loads that will feed.

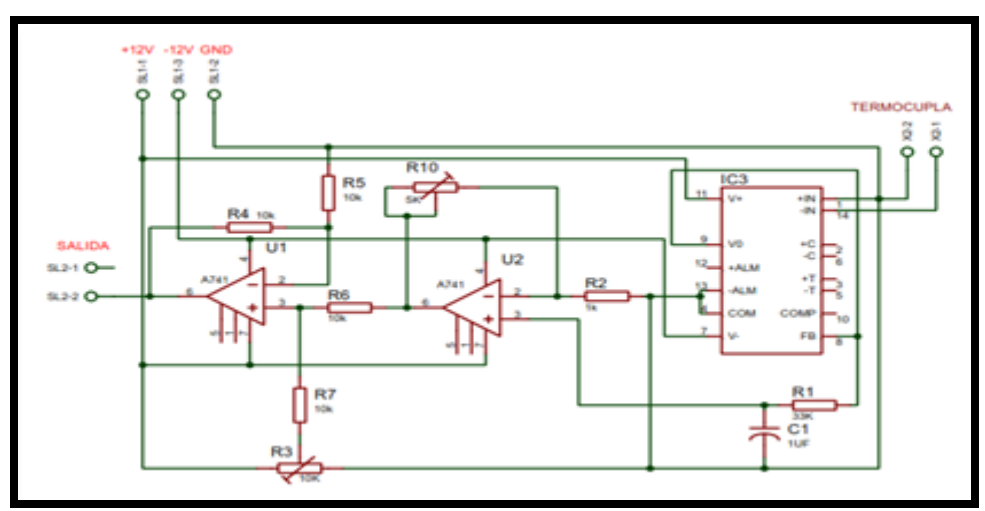

Figure 5: Schematic Diagram of the Signal Conditioning Circuit.

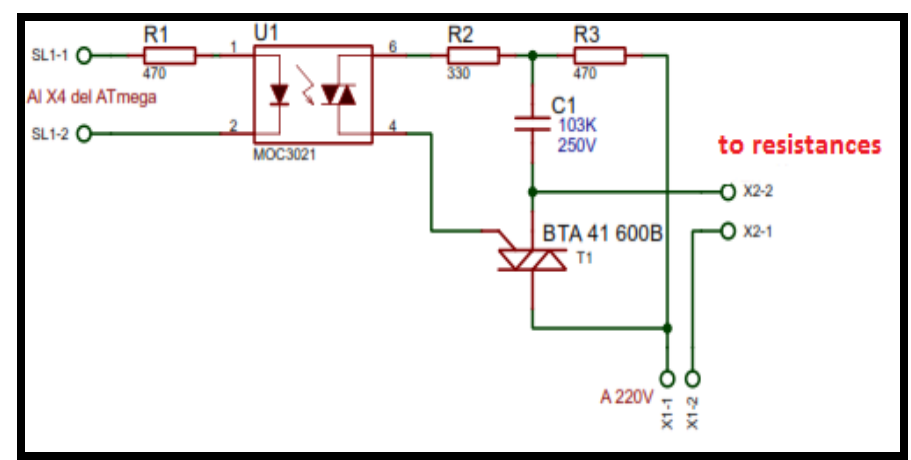

Figure 6: Schematic Diagram of Resistance Power Control. 


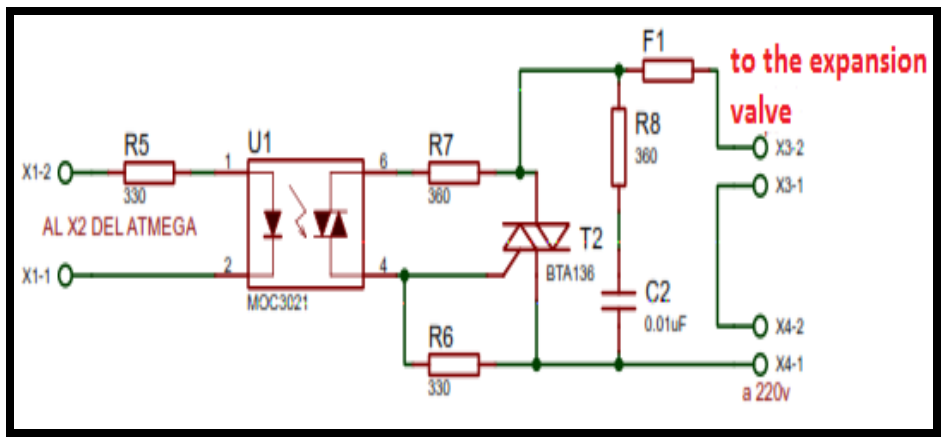

Figure 7: Schematic Diagram of the Valve Opening Control.

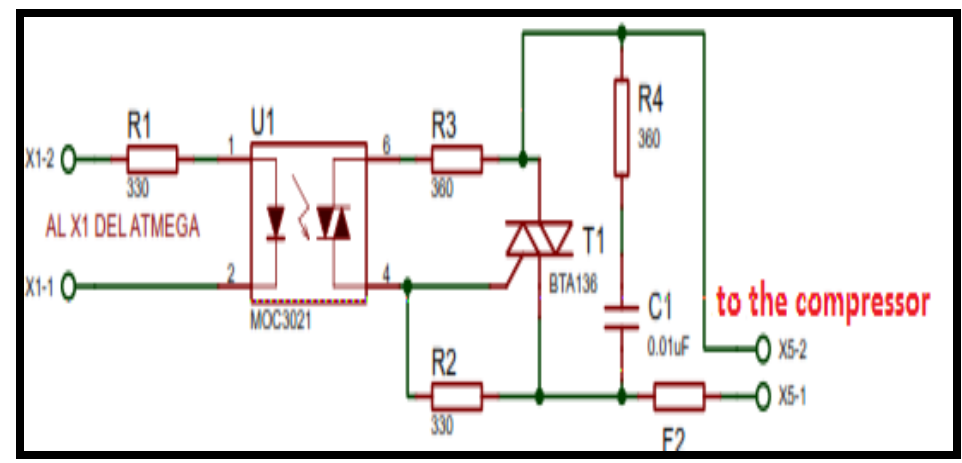

Figure 8 Schematic Diagram of the Valve Opening Control.

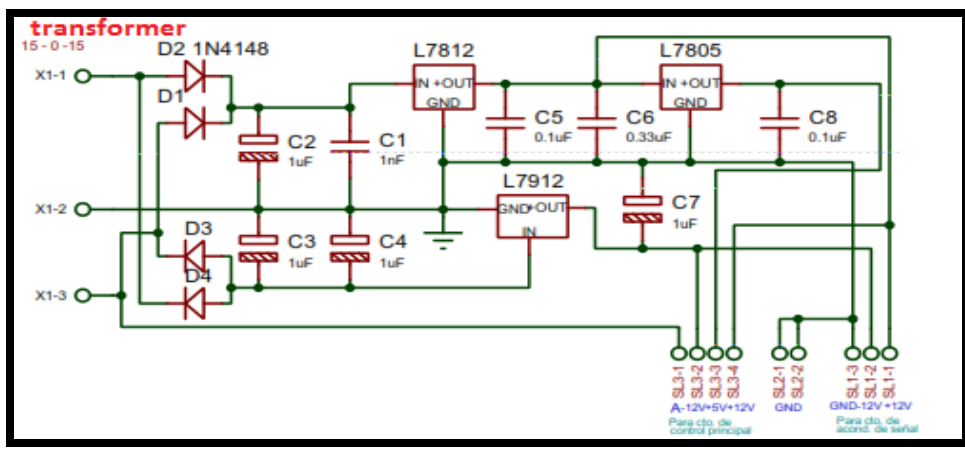

Figure 9: Schematic Diagram of the Power Supply.

\subsection{Software Design}

The designed hardware will not achieve the temperature control of the adiabatic chamber on its own, but requires software that complements it in addition to allowing all the system modules to be integrated and controlled. This part shows the most prominent parts presented by the developed software.

Main Program Design: The main program has been designed to have a particular functionality and integrate all the blocks shown above. It allows the entry of data, in this particular case, it will allow the entry of the temperature values to which the control will tend to arrive whenever they are within the operating range $\left(-20^{\circ} \mathrm{C}\right.$ and $\left.80^{\circ} \mathrm{C}\right)$. It also allows the entry of the time during which it is desired that the previously entered temperature remains.

Figure 10 shows the program starts by saving the value of the battery pointer, after which it proceeds to make the general settings that include the configuration of ports, interruptions, timers, LED handling, etc. Once the settings have been made, the program requests the desired temperature and after a subsequent validation requests the time during which the test is to be performed. 


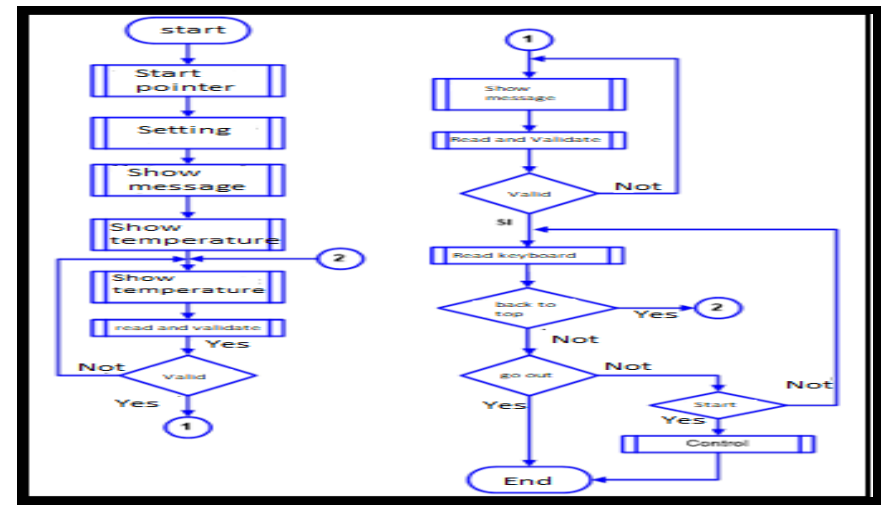

Figure 10: Flowchart of the Main Program.

\subsection{Connections Diagram}

In figure 11, it is presented as a diagram of connections of the designed circuits:

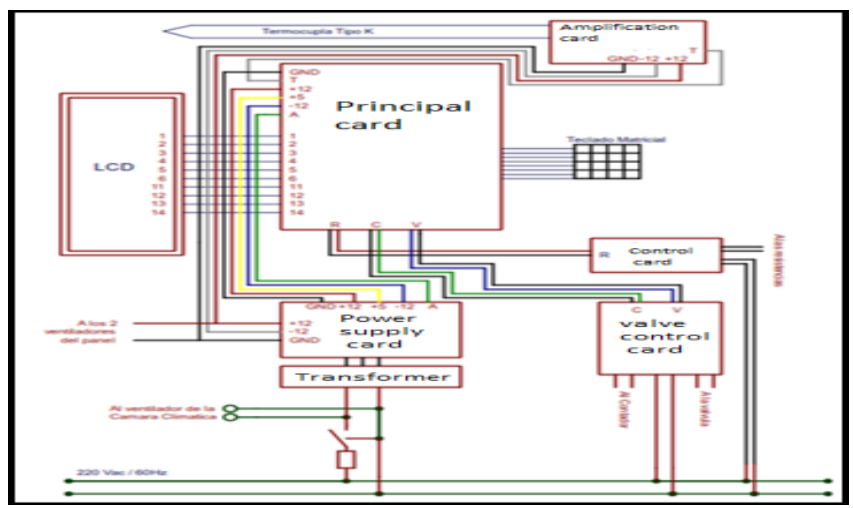

Figure 11: System Connections Diagram.

\section{RESULTS}

Tests and results with the expansion valve: Tests were performed with the valve control circuit and the compressor on / off circuit as a whole. On the recommendation of the manufacturer of the Danffos brand electronic expansion valve, the period of the PWM signal with which the valve worked was 6 seconds. The tests were started with a $100 \%$ duty cycle, which indicates that the valve will remain completely open. The results obtained are shown in Figure 12:

Figure 13 shows Control Type Selection: After analyzing the results obtained by testing the power of the resistors and the opening control of the valve to heat and cool respectively, it was decided that the type of control of the system be ON - OFF. This implies that upon reaching the desired temperature, the heating resistors will be turned off or the compressor will be turned off and the expansion valve will be closed as required.

Figure 14 shows Final results: This part shows the results obtained for two values within the operating range of the system, since in general the system starts from the ambient temperature (approx. $\left.25^{\circ} \mathrm{C}\right)$, a value above $\left(40^{\circ} \mathrm{C}\right)$ and another below were chosen. $\left(0^{\circ} \mathrm{C}\right)$ of said temperature whereby the results of the control can be appreciated using the resistors and the electronic expansion valve.

The temperature dropped in approximately 18 minutes from $32{ }^{\circ} \mathrm{C}$ to $0{ }^{\circ} \mathrm{C}$, after which it was attempted to maintain at that temperature. Table 2 and Graph 12 show how the temperature varies when exercising the ON / OFF control. 


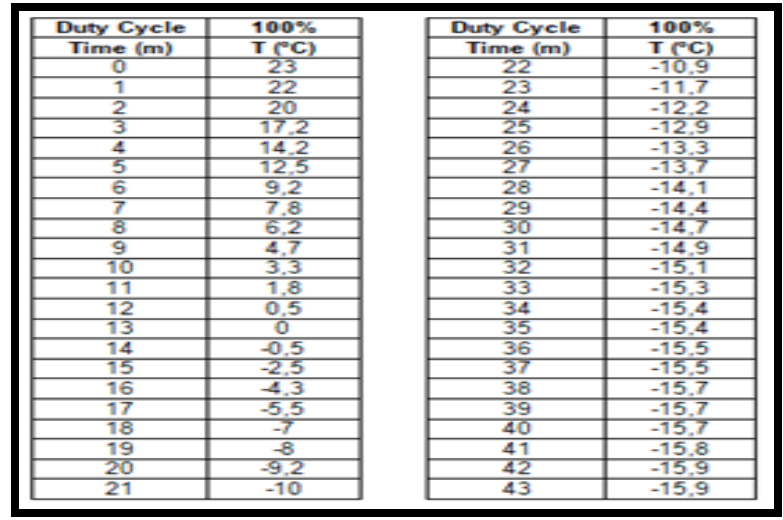

Figure 12: Temperature Values Over Time.

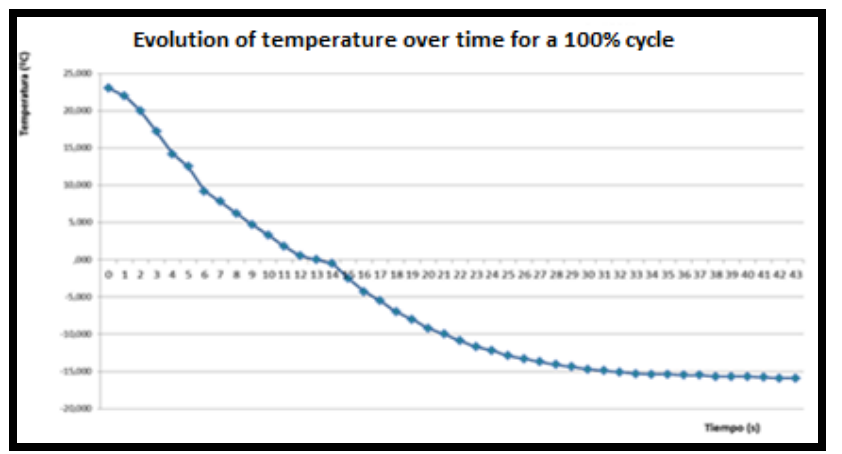

Figure 13: Evolution of Temperature Over Time.

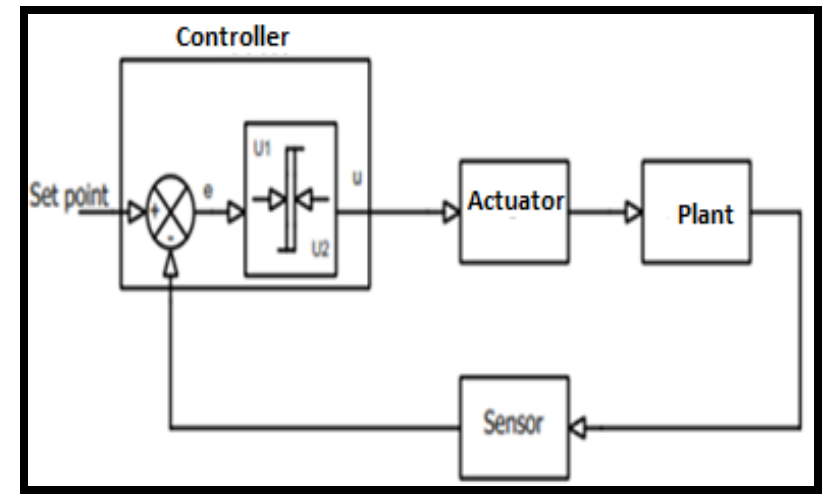

Figure 14: On-Off Controller Model.

\begin{tabular}{|c|c|c|c|c|c|}
\hline Time (s) & $\mathrm{T}\left({ }^{\circ} \mathrm{C}\right)$ & Time (s) & $\mathrm{T}\left({ }^{\circ} \mathrm{C}\right)$ & Timd (s) & $\mathrm{T}\left({ }^{\circ} \mathrm{C}\right)$ \\
\hline 0 & -0.5 & 200 & 24.5 & 400 & -0.5 \\
\hline 10 & $-0,3$ & 210 & 24 & 410 & $-0,6$ \\
\hline 20 & $-0,2$ & 220 & 23,5 & 420 & $-0,5$ \\
\hline 30 & $-0,1$ & 230 & 23,2 & 430 & $-0,4$ \\
\hline 40 & 0 & 240 & $-0,3$ & 440 & $-0,3$ \\
\hline 50 & 0.1 & 250 & $-0,2$ & 450 & $-0,1$ \\
\hline 60 & 0.2 & 260 & $-0,1$ & 460 & 0 \\
\hline 70 & 0,3 & 270 & 0 & 470 & 0,1 \\
\hline 80 & 0.4 & 280 & 0,1 & 480 & 0,2 \\
\hline 90 & 0,5 & 290 & 0.2 & 490 & 0,3 \\
\hline 100 & 0,5 & 300 & 0,3 & 500 & 0,4 \\
\hline 110 & 0.4 & 310 & 0.4 & 510 & 0.5 \\
\hline 120 & 0,3 & 320 & 0,5 & 520 & 0,6 \\
\hline 130 & 0,2 & 330 & 0.4 & 530 & 0.7 \\
\hline 140 & 0,1 & 340 & 0,3 & 540 & 0,7 \\
\hline 150 & 0 & 350 & 0,2 & & \\
\hline 160 & $-0,1$ & 360 & 0 & & \\
\hline 170 & $-0,2$ & 370 & $-0,1$ & & \\
\hline 180 & $-0,3$ & 380 & $-0,2$ & & \\
\hline 190 & -0.4 & 390 & -0.4 & & \\
\hline
\end{tabular}

Figure 15: Desired Temperature Values. 


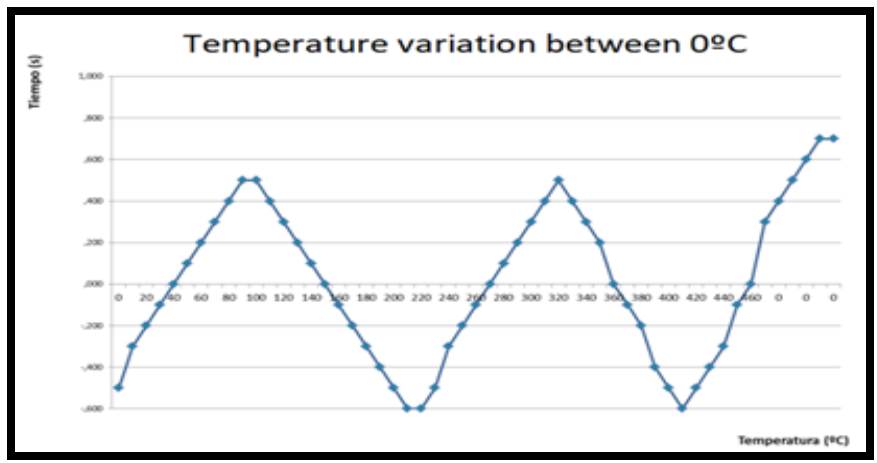

Figure 16: Temperature Variation Between the Desired Value $\left(0^{\circ} \mathrm{C}\right)$.

\section{CONCLUSIONS}

Once the design of the temperature control system for the adiabatic chamber of the energy laboratory has been completed and after having performed the necessary tests, the following conclusions have been reached:

The use of a signal conditioning stage provided by the thermocouple makes it possible to make better use of the $\mathrm{ADC}$ of the Atmega8; reason for which it was possible to show the temperature with a resolution of $0.1^{\circ} \mathrm{C}$ working within the range of $-20^{\circ} \mathrm{C}$ to $80^{\circ} \mathrm{C}$.

The use of an offset in the conditioning of the signal from the thermocouple also allows minimizing the error it presents.

The use of the heating resistors and the cooling system allow the temperature limit values to be reached within the range to be controlled.

The Atmega8 microcontroller was sufficient to correctly handle the designed modules, that is, work with the user interface (Keyboard and LED), the cooling, heating and signal conditioning modules.

The proper use of electrical isolation stages allowed the normal working of the three power circuits that are available (resistance control, valve and ignition of the compressor), without jeopardizing or damaging the control part, whose main component is the Atmega8 microcontroller, this was achieved with the use of optocouplers.

\section{REFERENCES}

1. Bryan Klofas, Karl Van Dk, Rick Doe. SRI International. (2013). "CTEC: CubeSat Thermal Environment Chamber". CubeSat developer's conference. San Luis Obispo, CA.

2. Johannes, Karl (2017) A Concise Introduction to Additives for Thermoplastic Polymers.Estado Unidos: Scrivener Publishing.

3. Mathias Militzer, Warren J. Poole. (2014). "Precipitation Hardening of HSLA steels". Materials Technology. Steel Research 69.

4. Ogata, Katsuhiko, (2016). Ingeniería de Control Moderna. Cuarta Edición. México D.F : Prentice Hall.

5. Rösler, Joachim/ Harders, Harald/ Bäker, Martin, (2014), Mechanisches Verhalten von Werkstoffen, B.G. Editorial Teubner, Wiesbaden Smith, William F. (2013). "Fundamentos de la Ciencia e Ingeniería de Materiales". Editorial McGraw-Hill. Segunda Edición. España.

6. TeTechnology, Inc. VT-199-1.4-0.8 Thermoelectric Module (Peltier Module) Specifications. http://www.tetech.com/temodules/graphs/VT-199-1.4-0.8.pdf. 